\title{
S. Kay, Parrots and Nightingales. Troubadour Quotations and the Development of European Poetry
}

\section{Walter Meliga}

\section{(2) OpenEdition}

1 Journals

\section{Edizione digitale}

URL: http://journals.openedition.org/studifrancesi/10502

DOI: 10.4000/studifrancesi. 10502

ISSN: 2421-5856

\section{Editore}

Rosenberg \& Sellier

\section{Edizione cartacea}

Data di pubblicazione: 1 décembre 2017

Paginazione: $524-525$

ISSN: 0039-2944

\section{Notizia bibliografica digitale}

Walter Meliga, «S. Kay, Parrots and Nightingales. Troubadour Quotations and the Development of European Poetry», Studi Francesi [Online], 183 (LXI | III) | 2017, online dal 01 février 2018, consultato il 24 janvier 2021. URL: http://journals.openedition.org/studifrancesi/10502 ; DOI: https://doi.org/10.4000/ studifrancesi. 10502

Questo documento è stato generato automaticamente il 24 janvier 2021.

\section{(c)}

Studi Francesi è distribuita con Licenza Creative Commons Attribuzione - Non commerciale - Non opere derivate 4.0 Internazionale. 


\title{
S. Kay, Parrots and Nightingales. Troubadour Quotations and the Development of European Poetry
}

\author{
Walter Meliga
}

\section{NOTIZIA}

SARAH KAY, Parrots and Nightingales. Troubadour Quotations and the Development of European Poetry, Philadelphia, University of Pennsylvania Press, 2013, «The Middle Ages Series», $464 \mathrm{pp}$.

1 Il libro è dedicato all'analisi delle citazioni dei trovatori in opere letterarie (novas, poesia lirica, Jean Renart, Petrarca), paraletterarie (vidas e razos) e didascaliche (testi grammaticali, Breviari d'Amor, De vulgari eloquentia di Dante) occitane, catalane e italiane fino al sec. XIV. Esso parte dalla constatazione che, dopo la letteratura latina, la lirica trobadorica è la prima fra le letterature volgari a ricevere lo statuto di classico. L'autrice distingue fra ripresa o citazione in senso stretto (quotation) e riferimento all'interno di un'opera letteraria (citation), distinzione che permette di meglio comprendere l'ampio spettro (più di 600) di riprese dai trovatori che interessa le letterature considerate: la prima modalità è quella del pappagallo (parrot), focalizzata sulla conoscenza, la seconda dell'usignolo (nightingale), indirizzata invece all'espressione soggettiva, ed è sulla prima di esse che l'analisi principalmente si rivolge. Un ricco apparato di appendici, che comprende quasi la metà del libro (pp. 203-406), raccoglie tutti i dati riguardanti il numero e il tipo nonché la collocazione delle citazioni.

2 Per quanto interessante e stimolante in vari punti, il lavoro è però anche segnato da una certa tendenza alla sopravvalutazione e alla sovrinterpretazione della stessa procedura della citazione letteraria (sulla base delle speculazioni di Jacques Derrida e di Jacques Lacan), ritenuta (nelle due modalità) formatrice di una nuova capacità di 
espressione poetica del soggetto, fra «desiderio» e «conoscenza». La stessa critica si può avanzare nei confronti di fatti e condizioni di singole opere o tradizioni, assunte a significazioni improbabili e dipendenti invece dalle vicende della tradizione manoscritta ovvero dai modi di lettura e di riuso dei testi coinvolti. 